\title{
ENTRE AFICIONADOS Y ANTI-TAURINOS APUNTES PARA UNA DISCUSIÓN SOBRE LA TAUROMAQUIA SIN ESENCIALISMOS
}

\section{IN BETWEEN FANS AND ANTI BULLFIGHTING ACTIVISTS: POINTING OUT A DISCUSSION ABOUT BULLFIGHTING WITHOUT ESSENTIALISM}

\section{ENTRE FÃS E ANTI-TOURADAS: NOTAS PARA UMA DISCUSSÃO SOBRE AS TOURADAS SEM ESSENCIALIDADES}

\section{Páginas Diana Catalina Zapata Cortés \\ 30-45 catazapata07@hotmail.com}

\section{Recibido} 13 de octubre

Aceptado 15 de noviembre
Historiadora de la Universidad de Los Andes con maestría en Sociología de la Cultura y Análisis Cultural del Instituto de Altos Estudios Sociales (IDAES), Universidad Nacional de San Martín (UNSAM), Buenos Aires, Argentina. Investigadora del Centro de Estudios Afrodescendientes, Universidad Javeriana.

Este artículo es resultado de la investigación en torno técnica, subjetividad y poder propuestas en el seminario de Análisis de la Cultura en el marco de la Maestría en Sociología de la Cultura y Análisis Cultural. Universidad Nacional de San Martín (Argentina). 
Resumen

Este artículo reflexiona en torno a la polémica suscitada tras la decisión del gobierno distrital en el año 2012 de prohibir la celebración de eventos taurinos en Bogotá. Se argumenta que la discusión entre los movimientos anti-taurinos y los aficionados a la fiesta brava se establece sobre la episteme binaria civilización/barbarie, articuladora de diferentes experiencias de dominación material y simbólica de la modernidad. La polémica se analiza a partir de algunas intervenciones hechas por representantes de ambas partes encontradas, en foros de opinión y redes sociales. Se llama la atención sobre la necesidad de abordar esta discusión desde una perspectiva de cultura no esencialista, que haga posible dilucidar las bipolíticas que hay tras la conflictiva definición hombre-animal y superar los dogmatismos que permiten su fácil instrumentalización.

\section{Palabras claves}

Tauromaquia, movimientos anti-taurinos, civilización/barbarie, biopolíticas, redes sociales 


\section{Abstract}

This article reflects on the controversy incited by the decision taken by the government of Bogotá in 2012 that prohibited bullfighting in the city. It arguments that the discussion that locked anti-taurine movements and the aficionados of the fiesta brava established itself on the binary episteme civilization/barbarism that articulated different experiences of material and symbolical domination ingrained into modernity. The controversy in analyzed by focusing in the interventions made by representatives of the arguing parts found in opinion forums and social media. The article calls towards the necessity of assuming the discussion from a non-essentialist perspective of culture that enables to dilucidate the biopolitics behind the conflictive definition of human being and animal and that transcends the dogmatisms allowing its instrumentalization.

\section{Keywords}

Bullfighting, anti-taurine movements, civilization/ barbarism, biopolitics

\section{Resumo}

Este artigo reflete sobre a polêmica causada pela decisão do governo distrital no ano 2012 de proibir a celebração de touradas em Bogotá. Argumenta-se que a discussão entre os movimentos anti-touradas e fãs das touradas se estabelece sobre a episteme binária civilização/barbárie, articuladora de diferentes experiências de dominação material e simbólico da modernidade. A controvérsia é analisada a partir de alguns discursos feitos pelos representantes das partes encontradas, em fóruns de opinião e redes sociais. Chama-se a atenção sobre a necessidade de abordar esta questão a partir da perspectiva de cultura não esssencialista, que faça possível elucidar as biopolíticas que residem na conflitiva definição homem-animal e superar os dogmatismos que permitem sua fácil instrumentalização.

\section{Palavras-chave}

touradas, movimentos anti-touradas, civilização/

barbárie, biopolíticas, redes sociais 
"El conflicto político decisivo que gobierna todo otro conflicto es, en nuestra cultura, el conflicto entre la animalidad y la humanidad del hombre. La política occidental es, pues, co-originariamente biopolítica” (Agamben, 2006).

\section{Introducción}

Un día cualquiera, generalmente a principio de año, en medio de la feria taurina Nuestro Señor de Monserrate, entre la carrera 7 con calle 26, se detona un ambiente enrarecido y convulsionado, muchas veces cercado y vigilado por la figura estoica e intimidante de la policía antidisturbios de Bogotá. Ahí mismo, al pie del Planetario Distrital y junto al parque de La Independencia, donde cien años antes se cumplía la exposición agrícola e industrial en demostración del arribo de la modernidad, el progreso y la civilización a Colombia. En las afueras de la plaza están los jóvenes, a veces no tan jóvenes, de jeans desgastados, camisetas negras y estampadas artesanalmente, botas o zapatillas deportivas, mochilas, banderas y proclamas. Gritan a sus adversarios ¡Cavernícolas! ¡Barbaros! ¡Salvajes! ¡Sádicos! ¡Enfermos mentales! Mientras tanto, de las tribunas salen con los atuendos sofisticados, para mostrar y exhibir, representantes de la elite bogotana, políticos, empresarios, periodistas y también gente del común seguramente de una clase media acomodada. En su momento no dicen nada, salen por los corredores vigilados y días más tarde responden por los medios de comunicación a las acusaciones hechas por los agolpados manifestantes con expresiones parecidas: "hipócritas" "irracionales" "fanáticos" "retrógrados" "ignorantes” y “abusivos”.

A pesar de varios de mis buenos amigos, movilizados hoy por las nuevas sensibilidades instaladas dentro del discurso hegemónico y global sobre la protección a la naturaleza y los derechos de los animales, no tengo por objetivo hacer un juicio moral en contra de los aficionados a la tauromaquia. Sin embargo, tampoco me propongo hacer una defensa en el vacío de las corridas de toros a partir de un “todo vale" sustentado en el discurso liberal, hoy radicalizado por el neoliberalismo, sobre las libertades individuales y la celebración del multiculturalismo como actitud actual hacia las diferencias. Por el contario, este ejercicio tiene como propósito rescatar algunas de las aristas y ambigüedades que conforman está polémica, llamando la atención sobre la necesidad de superar los dogmatismos y esencialismo en que hoy en día es atrapada dicha discusión, y que permite su fácil ideologización e instrumentalización política.

Argumento que la actual discusión entre los movimientos anti-taurinos y los aficionados a la tauromaquia se establece a partir de la episteme binaria civilización/barbarie propia del pensamiento eurocéntrico y vector articulador de las diferentes experiencias de dominación material y simbólica de la modernidad/colonialidad. Quiero mostrar cómo este encapsulamiento desarraiga la discusión de sus respectivos contextos políticos, culturales e históricos, simplificando así el conflicto en dos posiciones antagónicas y dogmáticas que se valen de un sistema de representaciones estereotipado del enemigo o el opositor. Dicha dinámica facilita la instrumentalización de la polémica con fines políticos o económicos, develándose así el biopoder que se cierne tras la frágil frontera que separa lo animal de lo humano. Propongo encarar la discusión sobre la tauromaquia desde un concepto de cultura no esencialista capaz de oponerse a la cosificación de la "vida" que se produce en aquellas dinámicas hegemónicas que intentan incesantemente construir a un "otro" residual como el animal, al que se puede utilizar, o al enemigo al que se puede eliminar o dominar 


\section{Bogotá, ¿una ciudad anti-taurina?}

Los movimientos anti-taurinos cuentan con una importante trayectoria en los países antiguamente colonizados por España, donde actualmente se practican corridas de toros. Sin embargo, la presente reflexión se realiza a partir del caso específico de Bogotá. A comienzos del 2012, el Alcalde Mayor de la capital revocó el contrato de administración de la plaza de toros La Santa María que tenía la Corporación Taurina; entidad encargada de celebrar anualmente la temporada de toros en esta ciudad y en el resto de capitales donde hay actividad taurina periódicamente como Medellín, Cali y Manizales. Brevemente sintetizaré los contextos jurídico y político que enmarcaron esta discusión, en aras de dimensionar una controversia que alcanzó un lugar privilegiado en el debate público y político en Colombia en los últimos años.

Sin dejar de ser un tema de discusión y tensión entre paradigmas jurídicos, la fiesta brava en Colombia es constitucionalmente reconocida como una actividad cultural. Particularmente es uno de los casos donde se declara en excepcionalidad el deber, también constitucional, de protección animal que prohíbe tanto su maltrato como todo tipo de actividad que implique crueldad en su contra. Las corridas son reconocidas legalmente como una de las manifestaciones culturales que deben respetarse acorde al sentido pluralista e incluyente invocado en la Constitución de 1991, donde también se otorga valor absoluto a la cultura como matriz productora de identidades en una sociedad que se presenta ante el mundo como multicultural. Es de notar, sin embargo, que esta disposición ha sido varias veces demandada y cuestionadas por voces provenientes de los movimientos animalista, siendo en todos los casos fallada a favor de la fiesta brava. ${ }^{1}$

1 Ver página de la Corte Constitucional de Colombia, "Sentencia C-666/10"

http://www.corteconstitucional.gov.co/relatoria/2010/c-666-10. htm (Recuperado el 18 de febrero de 2013)
Esta protección constitucional implica una jerarquía normativa frente a cualquier medida tomada por autoridades regionales o locales, motivo por el cual los hechos sucedidos en Bogotá, y meses antes en Medellín, desataron una agitada discusión que enardeció las pugnas entre los diferentes intereses y grupos afectados con tal decisión. Ante la falta de facultades legales para prohibir directamente la celebración de las corridas, el alcalde de la capital optó por un camino administrativo. El contrato anual de arrendamiento que poseía la Corporación Taurina sobre la plaza de toros no fue renovado para la temporada del 2012. Dicha medida fue argumentada dentro del plan de desarrollo Bogotá Humana que la nueva administración adoptó meses antes como su principal carta de navegación, en la cual entre muchas otras disposiciones se prohibió el uso de bienes de interés público para toda actividad que implicara maltrato o violencia contra los animales. Esta medida fue uno de los primeros actos de gobierno del para entonces, nuevo mandatario, respondiendo así a una sus principales promesas de campaña, que meses antes había logrado el apoyo de un heterogéneo grupo de fuerzas sociales en su mayoría de centro-izquierda, un importante grupo intelectual y un amplio sector representante de la juventud, principal y más activo componente de los movimientos anti-taurinos.

De inmediato, los aficionados y los representantes de los grupos económicos afectados con la decisión, como ganaderos y agentes del sector turístico, respondieron enérgicamente alegando argumentos de tipo económico, político, cultural y jurídico. Incluso un grupo de reconocidos intelectuales, caracterizados por sus posiciones disidentes frente a las posiciones autoritarias y reaccionarias que han dominado el campo político en las últimas décadas en el país, se manifestaron a favor de las corridas a través de un manifiesto colectivo que circuló en diferentes medios de comunicación y que dejó perplejos a muchos de sus lectores habituales. ${ }^{2}$ A pe-

2 El manifiesto puede ser consultado en el siguientes enlaces: http://plataformataurinadelperu.blogspot.com.ar/2012/01/ 
sar de algunas posiciones bien argumentadas, en la mayoría de casos los puntos críticos y problemáticos de esta actividad fueron opacados por acusaciones provocadoras y reduccionistas tanto de la medida, como de los movimientos animalistas y de la gente simpatizante con la decisión.

Meses más tarde, la Corte Constitucional se pronunció recordando el amparo jurídico que tienen las corridas de toros en Colombia, sobre las cuales, de acuerdo con lo dicho, no deben recaer acciones "riesgosas y jurídicamente injustificadas de las autoridades locales" (Las corridas de toros en Bogotá: cambio de tercio, 2012). El gobierno distrital le hizo quite a dicho pronunciamiento argumentando la calidad administrativa de la decisión, además de respaldarla bajo el pretexto de un supuesto proceso de remodelación previsto para dicho escenario. Así mismo, animadas por las autoridades distritales, a lo largo del 2012 fueron convocadas varias marchas en oposición a las prácticas que involucran violencia en contra de animales, teniendo una recepción positiva en un importante número de personas, entre militantes de movimientos animalistas y gente del común sensibilizados con dicha causa.

En el año 2013 la Corporación Taurina interpuso una acción de tutela frente a la medida prohibicionista, argumentando una mala interpretación de parte del mandatario Distrital de la sentencia constitucional C-666 del 2010, referente a la regulación de actividades taurinas, riñas de gallos, coleo y corralejas. Mientras el Alcalde sostiene que en dicha sentencia se prohíbe todo tipo de actividad que involucre sufrimiento animal o torturas, la Corporación arguye, en cambio, que allí también quedó constancia que ninguna administración local puede prohibir la celebración de corridas en aquellos lugares donde se demuestre que existe una tradición taurina y se celebren regularmente, como es el caso de la capital. Así mismo, recordó que solamente es

manifiesto-taurino-de-antonio-caballero.html http://www.eltiempo.com/archivo/documento/CMS-10945057 (Recuperado el 18 de febrero de 2013) facultad del poder legislativo "humanizar" y regular la fiesta brava, por ejemplo, ordenando eliminar la muerte del animal del espectáculo. La decisión fue aplazada por la Corte para ser tomada a comienzos del 2014, sin haber algún pronunciamiento al respecto hasta el momento. Finalmente vale la pena señalar que, a pesar de estos últimos años de embrollo jurídico, los aficionados a la fiesta brava decidieron trasladar las habituales corridas de comienzos de año a municipios cercanos a la capital, donde existen plazas de toros de tercera categoría o en algunos casos improvisando escenarios.

Más que una descripción detallada de los acontecimientos, me interesa resaltar las disputas que se detonan tras la decisión anti-taurina entre diferentes intereses políticos y económicos, que buscan legitimidad a partir de la polarización que se genera entre las pasiones y enemistades de aficionados y anti-taurinos. Sin lugar a duda, las reivindicaciones de los movimientos animalistas actuales ponen de manifiesto la urgente necesidad de revisar una costosa forma de organización y distribución de la vida, producida y conocida históricamente como capitalismo. No obstante, la controversia desatada en Bogotá, más que expresar un cambio frente a prácticas instauradas en la cultura que implican tortura, sufrimiento o dolor; nos invita a pensar en esa lucha constante por definir las formas legitimas de enunciar y mostrar la violencia, en donde se enraíza el poder para administrar la vida y distribuir la muerte (Foucault, 1977). El alcance adquirido por esta discusión es por lo tanto, revelador de la biopolítica que se cierne tras la articulación de categorías como "animalidad" y "humanidad" 3 a partir de las cuales es posible instrumentalizar cualquier forma de vida que se construye como un exterior constitutivo: el "inmigrante”, el "negro”, el "indígena”, el

3 Entiendo estas categorías no como conceptos científicos o biológicos estables y universales, sino desde una perspectiva posestructuralista como indicadores epistemológicos que permiten constituir articulaciones necesariamente históricas sobre "lo viviente", en tanto sistemas jerárquicos de diferenciación y clasificación a partir de una serie de oposiciones y facultades funcionales (Agamben, 2006; Espósito, 2007) 
"homosexual" etcétera. En este caso el "animal" como lo expresa la caricatura siguiente

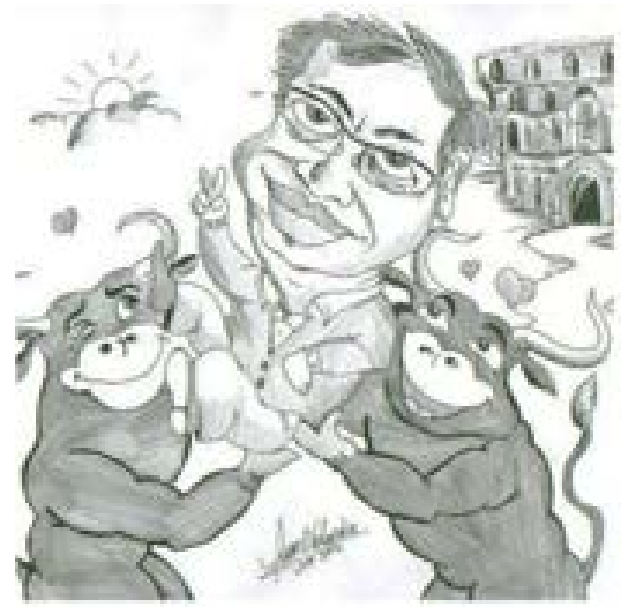

Figura 1: Esta imagen circuló en las redes sociales días después de la controversia. El personaje que aparece en los hombros de los dos toros es Gustavo Petro, el para entonces alcalde de Bogotá y responsable de las acciones en contra de las corridas. ${ }^{4}$

Un escenario de controversia similar es el de Cataluña, donde en el 2010 el Parlamento tomó la decisión de prohibir las corridas. Sin desconocer la importancia de la militancia de las agrupaciones animalista de significativo crecimiento y fortalecimiento en los últimos años, los defensores de las corridas de toros consideran la decisión como una jugada nacionalista por parte del Parlamento, teniendo en cuenta que la tauromaquia es considerada además como uno de los principales símbolos españoles. ${ }^{5}$ Así mismo, en Perú después de una controversia similar, el Tribunal Superior definió la fiesta brava como bien de interés público, mientras que en Ecuador, también un país con tradición taurina, hay una fuerte tendencia a su rechazo.

4 Esta imagen fue tomada de la cuenta de twitter @rochizitaparra (2013-12-11 08:45:27). Se puede consultar en el siguiente enlace: http://twicsy.com/i/WWDjwh

5 Para mayor información ver:

http://www.periodistadigital.com/opinion/cultura/2011/09/26/ generalitat-monumental-toros-taurino-cornas-serafinprohibicion-nacionalismo.shtml

(Recuperado el 18 de febrero de 2013)

\section{Un "tropos" binario comoarticulador de la discusión: hombre/animal- civilización/barbarie}

Apoyada en el desarrollo teórico de Greogorio Agamben, en esta parte de artículo me propongo mostrar cómo los argumentos sostenidos tanto por defensores y opositores de la fiesta brava se estructuran sobre la aporía hombre-animal, propia del pensamiento occidental articulado en torno a la episteme binaria civilización-barbarie. Parto de la consideración que dicha frontera no es un asunto estrictamente biológico, ni una cuestión de orden metafísico o filosófico, sino ante todo una cuestión de orden práctico como "operación metafísico-política fundamental, y en la cual solo algo así como un 'hombre' puede ser decidido y producido" (Agamben, 2006, p. 47) en condiciones históricamente situadas. Considero que esta tensión se corresponde con un sistema discursivo que representa al diferente, en este caso el "otro" opositor, como salvaje, bárbaro, primitivo. Es decir, a través de su acercamiento a la naturaleza y a su animalidad como forma de negar su plenitud ontológica en tanto hombre, y por lo tanto como demostración de su inferioridad. En esa lábil frontera hombre-animal está en juego el campo de "lo viviente" sujeto a las tecnologías del biopoder, mientras que en lo residual constitutivo subyace el objeto sobre el cual la inercia del poder soberano reclama el derecho a exigir la muerte y administrar las formas legítimas de mostrar la violencia.

\section{Los anti-taurinos: el vector romántico como articulador de la discusión}

Uno de los primeros elementos que se resalta en los argumentos esgrimidos por los anti-taurinos es la presupuesta capacidad moral de lo humano para discernir entre lo justo e injusto, lo bueno y lo malo, lo verdadero y lo falso. Alma, razón, inteligencia, configuran entonces ese particular que en condiciones ideales alejarían al hombre de su esta- 
do salvaje y lo diferenciarían del resto de animales dentro del sistema jerárquico de "lo viviente". De acuerdo con este razonamiento, el enfrentamiento entre hombre y toro no puede ser considerado entonces como una lucha entre iguales y por lo tanto, justa. Tanto desde una moral religiosa o una ética secular, los aficionados a la fiesta brava son entonces acusados de carecer o tener deformada dicha capacidad. A partir de algunas de las opiniones que circularon en la web, a continuación analizo la manera como los argumentos anti-taurinos resuelven dicha dicotomía.

La tal Fiesta Brava NO es una actividad cultural. Es una actividad cruel y sangrienta que ignora el dolor y el sufrimiento de los animales que Dios colocó en este planeta para compartirlo con esta Raza Humana, esa que comete muchos desatinos, brutalidades y monstruosidades inhumanas dignas de muchos desalmados. ${ }^{6}$

La opinión anterior nos abre la puerta para ver la centralidad que tiene el establecimiento de la frontera hombre-animal en la estructuración del argumento anti-taurino. Dios habría creado diferentes formas de vida para compartir el planeta; por un lado los animales, en genérico, que aparecen representados como un todo homogéneo y compacto, frente a una especie particular que se diferencia en término de "raza humana". Llama la atención

6 Las citas incluidas en este aparatado fueron tomadas en su mayoría en los foros de opinión que acompañaron los siguientes artículos. No obstante, hay que anotar que argumentos semejantes pueden ser encontrados en los diferentes foros de opinión que se abrieron en su momento a propósito de la discusión:

El Espectador (13/10/2012). "Sólo un bárbaro no distingue entre un humano y un animal”.

http://www.elespectador.com/noticias/nacional/solo-unbarbaro-no-distingue-entre-un-humano-y-un-animaarticulo-384540

El Espectador (02/11/2012). "Sabater, ética bestial” http://www.elespectador.com/tags/tauromaquia?page $=4$ El Espectador (08/02/2013). "La farsa de la tauromaquia" http://www.elespectador.com/opinion/farsa-de-tauromaquia (Recuperado el 20 de marzo de 2013) la apelación al concepto "raza” como recurso retórico para configurar un sistema de clasificación y jerarquización que necesariamente es activado en la anterior expresión. El uso de dicha palabra automáticamente despliega un conjunto de significados asociados a uno de los mayores dispositivos de dominación de la modernidad. Ello es la racialización de las diferencias, como un sistema de clasificación de la población que se vale de un conjunto de rasgos físicos y marcaciones corporales para establecer jerarquías y naturalizar desigualdades que son producidas en medio de relaciones de poder históricamente situadas (Hall, [1997] 2014).

Más allá del peligroso contenido ideológico que reviste la alusión a este concepto, los linderos de lo "humano" aparecen definidos por oposición a lo "inhumano". Las actividades crueles y sangrientas son consideradas propias de seres desalmados, siendo el alma aquel garante que permite discernir entre lo bueno y lo malo, y en esta medida abstraer el sentido de justicia que se necesita para alejarse de las actitudes crueles y sangrientas. El razonamiento anti-taurino pareciera acercarse en este punto al argumento de Alexandre Kojève que reconstruye Agamben (2006: 28): lo humano solo tiene lugar en la medida que es capaz de trascender y transformar la animalidad antropófora que lo sostiene. Es decir, solo a través de una acción negadora, el hombre es capaz de dominar y eventualmente destruir su propia animalidad. En consecuencia, el gusto por las corridas donde la exposición de la muerte violenta por acción voluntaria del hombre configura el acto ritual, no puede ser considerada propia de seres dotados con sentido de justicia como se hace explícito en la siguiente expresión: "Los españoles dejaron esta costumbre macabra que ningún ser justo tiene que valorar como cultura o costumbre”.

Por fuera de la matriz religiosa, el alma se repliega en la razón o la "inteligencia" como ese particular que modula el comportamiento, otorgándole al "hombre" una capacidad de entendimiento adi- 
cional que le hace posible regular y disciplinar sus instintos animales:

Entonces que vivan las peleas de perros, las de gallos y las de los hombres armados ya que son más parejas que las corridas de toros, se trata de luchas entre el mismo género y en igualdad de condiciones. En la de toros se trata de un ser irracional contra uno "inteligente", con ventajas porque está ayudado por otros igual de crueles y todos armados.

Aunque en la intervención anterior se utilizan comillas de forma irónica para enfatizar la distorsión o anomalía que se les atribuye a los aficionados taurinos, es precisamente esa acusación lo que permite inferir el presupuesto subyacente. La razón, entendida como inteligencia, es considerada aquello constitutivo y propio de "lo humano" que lo aleja y lo separa de su animalidad original. La "inteligencia" por lo tanto situaría al "hombre" en una condición de ventaja frente a su oponente: el toro irracional y salvaje, y por lo tanto indefenso. Desde esta perspectiva, la descalificación de la fiesta brava y de los aficionados no se da tanto por la obscenidad de sus actos, sino por la supuesta perturbación del valor absoluto de justicia del hombre racional ya que las corridas constituirían enfrentamientos desiguales entre aquel ser inteligente y el animal-toro indefenso.

Ya sea para demostrar el carácter injusto de la fiesta brava o rechazar la legitimidad de los argumentos taurinos, las diferentes opiniones expuestas establecen un juego de significados que opone hombre-alma-razón-justicia frente animal-salvaje-irracional-indefenso como una polaridad semántica y ontológica necesariamente excluyente. Sin embargo, es posible inferir un tercer lugar que excede dicha unidad binaria, reservado para la disfuncionalidad de aquella capacidad moral, esto sería lo "humano patológico". Tal anomalía no se resolvería entonces necesariamente en el retorno a una animalidad constituyente como un pasado original y primigenio del ser humano, sino en una tercera figura: lo monstruoso, lo bárbaro, lo abyecto y hasta lo demoniaco como lo manifiesta la siguiente alusión: "Esto decía el Papa Pío V sobre las corridas de toros: estos son sangrientos y vergonzosos espectáculos dignos de los demonios y no de los hombres”.

Por lo tanto, la sumatoria del estado salvaje y abierto de lo animal más el cálculo racional de lo "humano" escindido, tienen como resultado inesperado explícitamente lo degenerado: "estos degenerados no se dan cuenta que la época cavernícola ya pasó ¡Petro estamos contigo fuera la barbarie sádicos enfermos mentales! [sic]”. Entre lo animal y lo bestial pareciera residir el sentido de lo humano, un lugar siempre ausente, siempre incómodo. En la intensidad y furia con que se busca aislar ese humano patológico, proyectado en el adversario, se hace manifiesto aquello que George Steiner (2008) llama el hondo y atávico terror hacia un pasado genético. Una memoria que solo se puede experimentar a partir de un profundo temor de retorno a una animalidad constitutiva y heredada, que se decanta en la representación de lo bárbaro, cavernícola, macabro, demoniaco, degenerado y primitivo.

Con una mirada romántica y paternalista hacia el animal "no humano", los anti-taurinos buscan recomponer un vínculo perdido con un pasado primigenio que asusta a la vez que se anhela ante la aparente degeneración de la capacidad moral que le da sentido al hombre. Imposibilitado de escapar al develamiento de lo abierto, con una profunda incomodidad se mira con nostalgia y temor un lugar al cual ya le es imposible regresar. Se habla entonces en nombre del pasado remoto e idealizado representado en el estado salvaje del toro indefenso y débil ante los abusos del animal hombre, calculador y racional pero también habilitado con un hondo sentido de compasión; es decir, con la posibilidad de experimentar un sentimiento de dolor 
frente al sufrimiento injustificado de otro ser. Experiencia, a su vez, que solo se hace posible en la medida que el hombre permanece necesariamente atado a un "cuerpo [sintiente] irremediablemente tenso y dividido entre animalidad-humanidad" (Agamben, 2006, p. 28). Si lo humano solo es posible en medio de ese campo de tensiones dialécticas y cesuras, veamos cómo es resuelto este asunto en la defensa que hacen algunos de los aficionados a las corridas de toros.

\section{Los aficionado taurinos: la versión utilitarista y científica de la polémica}

Mientras que en los argumentos anti-taurinos la escisión hombre-animal es articulada a través de argumentos de carácter moral y ético, los asistentes a las corridas apelan a una perspectiva "científica" para establecer el distanciamiento necesario entre lo "humano" y lo "animal" que habilite el uso y provecho legítimo de esa naturaleza externa, dentro de la cual se incluye la dimensión ontológica de los animales "no humanos" como el toro de lidia. Siguiendo a Agamben (2006, p. 33), es esta acción de separar y dividir "precisamente lo que permite construir la unidad de la vida como articulación jerárquica de una serie de facultades y oposiciones funcionales”.

Uno de los puntos de mayor irritabilidad para los aficionados a la fiesta brava es la cuestión del sufrimiento que pueden experimentar los animales. En repetidas opiniones y enunciado de diferente maneras, el argumento taurino se concentra en demostrar que los toros de lidia no experimentan dolor cuando se enfrentan a la muerte proporcionada por el torero. A partir de la siguiente cita entremos al campo de tensiones hombre-animal que subyace a esta argumentación:
Que los toros reciben maltrato y sufren DOLOR en la corrida es una completa falsedad. Se parte de la comparación del toro con el ser humano, cuando son dos seres totalmente distintos. El toro bravo, especie salvaje modificada genéticamente, libera frente a determinados estímulos una serie de betaendorfinas que disminuyen el stress y el dolor. Su tálamo, que es un receptor de neurotransmisores, es un $20 \%$ superior al de otros bovinos. Al momento de recibir un puyazo, por ejemplo, libera 10 veces más cortisol que el que libera una mujer en un parto (Puntos en defensa de la fiesta brava, 2012). ${ }^{7}$

Lo primero a resaltar es la apelación a la ciencia moderna como principal criterio para legitimar y respaldar el argumento, lo cual le permite establecer una relación de objetivación, distanciamiento y extrañamiento frente a la relación que se establece entre el hombre y el animal. Se apela a datos en nomenclatura científica para demostrar ante todo que el toro no es un ser sintiente en términos humanos, y que por consecuencia no tiene capacidad para distinguir el sufrimiento en el camino hacía su muerte. La radicalidad de este argumento llega a sugerir incluso que en las corridas, el toro de lidia transita por una experiencia semejante al placer, como hace referencia la siguiente opinión:

Los toros en el ruedo liberan betaendorfinas, también conocidas como la «hormona de la felicidad», que bloquea los receptores de dolor en el sitio en el que este se está produciendo, hasta que llega un momento en que el dolor y el placer se equiparan y deja

$7 \mathrm{El}$ artículo completo puede ser consultado en la siguiente cuenta de facebook:

https://mobile.facebook.com/438248875014/photos/a.10150256 520300015.539313.438248875014/10150992378255015/?type=1 $\& \mathrm{p}=10$

(Recuperado el 20 de marzo de 2013) 
de sentirse dolor (El toro no siente dolor en la fiesta, 2007). ${ }^{8}$

Demostrar y comprobar que el toro no pasa por un estadio parecido al sufrimiento del hombre. De no ser posible producir una especie de "animal" a través de la manipulación genética que no sienta dolor a la hora de morir. Incluso llegar a modificar su sistema nervioso de tal forma que el dolor pueda ser reemplazado por placer. A estos argumentos recurren los defensores de las corridas para expurgar cualquier posible sentimiento de culpa. El afán por apartarse de cualquier diagnóstico de tortura o suplicio llega a tal punto que no solo es suficiente con negar el dolor y reemplazarlo con un supuesto goce. Se hace necesario demostrar que el toro lleva en su propia naturaleza, de antemano modulada o modificada por la acción humana, el destino trágico y heroico que le deparara para las corridas:

El toro de lidia no entra en ninguna de esas categorías. No es un animal salvaje, puesto que es criado por el hombre, ni un animal doméstico, puesto que cualquier tauromaquia supone la preservación de su instinto natural de hostilidad hacia el hombre llamado "bravura". Para este animal, una vida conforme a su naturaleza insumisa e indomable debe ser una vida libre y natural, y una muerte conforme a su naturaleza de animal bravo debe ser una muerte en la lucha contra aquel que atenta contra su libertad y le contesta a su supremacía en su propio terreno. Vivir libre y morir luchando es el destino del toro de lidia (Un retroceso moral, 2011). ${ }^{9}$

8 Ver artículo completo en el siguiente enlace: http://www.elmundo.es/suplementos/ cronica/2007/591/1172358004.html (Recuperado el 20 de marzo de 2013)

9 Ver artículo completo en el siguiente enlace: http://www.elmundo.es/suplementos/ cronica/2007/591/1172358004.html

(Recuperado el 20 de marzo de 2013)
¿Qué hace tan insoportable aceptar el dolor animal impartido por la acción voluntaria y consiente del hombre? Tal vez en la respuesta subyace también el temor hacia esa escisión nunca resuelta en donde se disputa el significado flotante de lo humano. En tanto el estatuto ontológico del toro como ser consciente de su cuerpo sintiente, pueda ser negado, los cuestionamientos y las sanciones morales hechas por los anti-taurinos pueden ser legítimamente rechazadas. En cambio si la ciencia, el principal y más poderoso dispositivo de poder-conocimiento de la modernidad, llegase a demostrar que el toro ciertamente pasa por un estado parecido al dolor, automáticamente se suscitaría un relevo ontológico que lo elevaría a una posición ventajosa de ser sintiente digno de la compasión humana. En otras palabras, entraría a formar parte de la misma naturaleza que el ser humano reservó para sí, aunque necesariamente en un estado de inferioridad.

Siendo así, las corridas se reducirían a meros actos sacrificiales como prácticas de sufrimiento hacia otro ser también sintiente pero indefenso frente a la acción voluntaria, racional y consiente del hombre. Si la distancia hombre-animal como parte de dos esferas ontológicas distintitas se desvanece, entonces las corridas se reducen a solo actos tortura desprovistos de cualquier valor ritual que justifique su celebración. El efecto "real” de esta operación a nivel ontológico, es que la fiesta brava es incorporada de forma automática dentro la lista de regulación y disciplinamiento de los dispositivos bipolíticos contemporáneos, donde se modelan nuevas subjetividades, cada vez más urbanas y alejadas del mundo rural, para las cuales deja de ser admisibles cualquier tipo de práctica que implique la exposición pública de sufrimiento y dolor animal.

Paradójicamente, el argumento taurino termina decantando en la misma incomodidad de sus opositores. Más que una justificación para validar el acto sacrificial que incluye la lidia de toros, lo que interesa demostrar es que las corridas no constitu- 
yen actos de violencia y crueldad contra seres sintientes pero "indefensos". De no ser posible, se apela al desarrollo técnico y las tecnologías genéticas para manipular una realidad que le sea soportable al "hombre", de manera tal que sus gustos puedan ser alejados de cualquier tipo de comportamiento fácilmente clasificado como patológico. En la negación de los aficionados a reconocerse como torturadores se oculta el mismo temor que se hacía evidente en los argumentos de los anti-taurinos. El temor a reconocerse en una animalidad que ya no le pertenece en la conciencia de esa escisión constitutiva donde se define el valor de lo "humano". En el recuerdo de un pasado genético vuelve a habitar el temor latente del retorno, que ya solo puede ser pensado a través de lo "humano patologizado". Un estado al que se teme, se le huye, se rechaza, y que se proyecta sobre un "otro" opositor como forma de poner en duda su plenitud ontológica como "hombre" y restar de esta manera legitimidad a sus argumentos como se refleja a continuación:

La lucha es titánica tratando de convencer a los irracionales animalistas, ecologistas y defensores de los animales que a los escenarios taurinos no va nadie obligado [...] El porqué de las corridas de toros, actividad milenaria y rito sacrificial que definitivamente no van a entender los retrógrados, abusivos e intolerantes anti taurinos, dejando ver su pobreza intelectual, cultural (La pobreza intelectual de los anti taurinos, 2012). ${ }^{10}$

Emerge entonces una de las aristas éticas más problemática que hay detrás de la discusión sobre la tauromaquia en la actualidad. Hasta qué punto se hace sostenible y se justifica la manipulación de la vida animal, sea lo que se entienda por ello, para satisfacer el entretenimiento del hombre. Uno de los intelectuales defensores de la fiesta brava en Colombia y parte activa de la controversia que se ha generado en los últimos tiempos, Alfredo Molano, justifica las corridas apelando a su origen como único ritual secular, herencia de la cultura popular de la América Española. En diferentes artículos de opinión, Molano se ha preocupado por explicar parte del conjunto de símbolos, significados y sentidos contenidos en la fiesta brava donde, según explica,

10 Ver artículo completo en el siguiente enlace:

http://opinionytoros.com/opinionytoros.php? $\mathrm{Id}=4367 \& \mathrm{Colab}=43$

(Recuperado el 20 de marzo de 2013) estarían sintetizados el sentido trágico y heroico de la vida. ${ }^{11}$

Más que poner en duda el contenido simbólico y ritual que personajes como Alfredo Molano recuerdan y valoran de la tradición taurina, me interesa pensar la discusión desde un concepto de cultura dinámico. Es necesario escapar de cualquier tipo de esencialismo y fundamentalismo que impidan ver la tensa trama de relaciones biopolíticas ocultas tras la definición de la conflictiva frontera hombre-animal, pues es allí donde se resuelven también las pugnas económicas, políticas y sociales que definen quién es digno de derechos y a quién, o qué, se le reserva el incómodo lugar de instrumentalización y cosificación.

Si bien la tradición taurina nació en el interior de la cultura popular hispanoamericana con un conjunto de significados asociados a contextos específcos, hoy en día es difícil pensarla por fuera de los circuitos y las dinámicas que se involucran en la industria del entretenimiento. De acuerdo con Schmucler (2011), el entreteniendo priva de autonomía la producción de valores culturales, constituyéndose así en la extensión del proceso de acumulación capitalista en el tiempo no productivo, lugar por demás donde se despliega el espíritu humano. Gran parte de los defensores actuales de las corridas son representantes de las elites involu-

11 Para ver algunos de los escritos de Alfredo Molano:

http://www.elespectador.com/opinion/columna366742-aficionados

http://www.elespectador.com/opinion/columna357920-ocultar-muerte

(Recuperado el 18 de febrero de 2013) 
cradas en el negocio que hay alrededor de la fiesta brava, oponiéndose principalmente a la decisión arguyendo la inviabilidad y el daño que representa en términos económicos. Más allá del cuestionamiento ético que se podría hacer al respecto, la circulación de este tipo de posiciones economicistas nos demuestran que la fiesta brava en la actualidad necesariamente hay que pensarla como parte de la oferta de entretenimiento nos ofrece el mercado, constituyéndose además en una escenificación de poder y prestigio social, lejos de pertenecer ya a la cultura popular, tal como lo analiza Lucas Ospina (2012) en su artículo "Páginas sociales: tauromaquia y poder”.

La relación que en la actualidad existe entre la tauromaquia y las múltiples ofertas que nos ofrece la industria cultural como entretenimiento y diversión, necesariamente nos obliga a reflexionar sobre la vigencia que puede tener el conjunto de significados con que nació la tradición taurina hace cerca de doscientos años en el contexto colonial español, donde seguramente el sacrificio ritual de un toro bravo tenía sentido como simbolización de la vida y la muerte. Así mismo, es necesario reflexionar sobre la sostenibilidad de una actividad que se lucra económica y simbólicamente a partir de la espectacularización de la muerte violenta de un animal, dentro de un contexto donde las nuevas subjetividades son configuradas y modeladas dentro del desarrollo de biopolíticas tendientes a regular y monopolizar las formas legítimas de enunciar la violencia.

Difícilmente puede llegarse a un lugar definitivo en las discusiones que se abren con respecto de la tauromaquia en el presente. Sin embargo, es en este campo de incertidumbre donde subyacen las posibles respuestas sobre la viabilidad del uso instrumentalizado y cosificado de un "otro", que con tan mala suerte queda mal clasificado dentro del sistema jerárquico de lo "viviente". Muchos amantes de la tauromaquia defienden su gusto haciendo un contrapunto con el funcionamiento de mataderos y criaderos de pollos, justificando su existen- cia a partir de la necesidad biológica que tiene el hombre de alimentarse. Tanto anti-taurinos como demás defensores de animales, a juicio de los aficionados, caerían en una supuesta contradicción al ser necesariamente consumidores de parte de esta industria alimentaria. Sin embargo, considero que el cuestionamiento ético y las repercusiones políticas siguen siendo las mismas ¿hasta qué punto la industria alimentaria realmente resuelve el hambre de la humanidad o simplemente hace rentable el negocio de "lo viviente" cosificado?

Tanto el funcionamiento de la industria alimentaria como el de la industria cultural, nos ayudan entonces a develar el carácter político que tiene el complejo fenómeno de la "vida”, más allá de su materialidad biológica o sus implicaciones metafísicas. Del establecimiento de un orden jerárquico de aquello llamado "viviente", depende esa fracción que puede ser legítimamente instrumentalizada por la rentabilidad capitalista, más allá de la necesaria producción de valores materiales, sociales y simbólicos en donde oscila el sentido de lo "humano". Una cosa es que el animal-hombre necesite alimentarse e inventarse a sí mismo a través de los espacios socialmente destinados al ocio, y otra cosa es hacer mercancía a un "otro" sintiente, cuya naturaleza ontológica solo existe y necesariamente depende de un denso campo de relaciones de poder donde es definido y redefinido constantemente de acuerdo a situacionalidades específicas y concretas.

\section{Reflexiones finales}

Me gustaría terminar este ejercicio con algunas aclaraciones de nivel metodológico y temático. La discusión sobre la tauromaquia toca muchos más aspectos que los desarrollados hasta el momento por este trabajo. Sin lugar a duda, es necesario reconocer esta discusión desde una perspectiva no reduccionista, capaz de deshilvanar el denso entrecruzamiento de aspectos culturales, éticos, económicos y políticos que se esconde tras el fuerte eco 
de un evento polémico como el que tuvo lugar en Bogotá en años pasados.

Particularmente, la elección de entrar y abordar dicha temática desde las asperezas biopolíticas involucradas, tuvo como propósito llamar la atención sobre el correspondiente carácter histórico que tiene tanto la tauromaquia como los movimiento anti-taurinos y, por supuesto, las actuales controversias desatadas en los diferentes países con tradición taurina vigente. Necesariamente hay que inscribir esta discusión dentro de un campo de confrontación de mayor envergadura, tocante con la escisión siempre irresuelta pero siempre problemática entre animalidad-humanidad; no entendida como esencia fija o absoluta, sino como ensamblaje histórico producido en medio de relaciones de poder y de saber, a su vez, generadoras de instituciones, prácticas y subjetividades localizadas en el tiempo y en el espacio.

Hasta que las actuales controversias entre aficionados taurinos y enardecidos anti-taurinos no consigan salir de cualquier intento de esencialismo moral u objetivación científica, no va a ser posible revisar y discutir sin dogmatismos o prejuicios el lugar que tiene hoy en día la fiesta brava como práctica cultural en ciertos lugares de influencia hispánica, frente a la necesaria tensión que se produce como mercancía cultural puesta a disposición y "libre elección", por la lógica economicista de la industria del entretenimiento contemporánea. De manera semejante, solo hasta que esta discusión sea ubicada dentro de su respectiva situacionalidad histórica, va a ser posible ahondar sobre la función y el lugar que ocupan las corridas de toros dentro de escenarios sociales cada vez más urbanos, productores de nuevas subjetividades, para las cuales deja de ser admisible y tolerable la relación de proximidad hombre-animal propia de contextos más rurales.

Una perspectiva compleja del entramado social y una articulación desde un concepto de cultura no esencialista, podrían funcionar como garantes de una discusión sobre la tauromaquia desde un nivel de reflexividad que impida caer en estereotipos, posiciones dicotómicas y fundamentalismos. En última instancia, este trabajo tuvo como propósito más que defender alguna de las dos posiciones, llamar la atención sobre la necesidad de rechazar cualquier tipo de reduccionismo que facilite la instrumentalización que tantos intereses economicistas como políticos hace de la pugna incesante por el ordenamiento legítimo de lo "viviente", en donde se define y se pone en juego constantemente el sentido de lo "humano".

Termino esta reflexión con un par de anotaciones finales. Escogí un conjunto indistinto de opiniones encontradas en varios foros de sitios web que publicaron noticias o artículos relacionados con la polémica librada en el 2012. La selección de las diferentes opiniones y expresiones estuvo lejos de ser trabajo acuciado de recopilación y sistematización de fuentes. Sin embargo, propuse una articulación de voces tal que me permitiera reflexionar sobre las aristas biopolíticas que hay detrás de la discusión anti-taurina. Sin querer justificar el poco rigor metodológico, es necesario reconocer la heterogeneidad, polifonía y los diferentes niveles de elaboración que se pueden encontrar dentro de los argumentos de aficionados y anti-taurinos. Sin querer desconocer la "originalidad" y la personalidad que hay detrás de cada expresión, con fines metodológicos me atreví a manejar la información como un solo cuerpo, precisamente con el objetivo de mostrar que detrás de las diferencias, divisiones y particularidades subyace una misma aspereza, la nunca resulta pero siempre incomoda separación entre el "hombre" y el "animal".

De manera parecida quisiera llamar la atención sobre el uso genérico de las categorías "hombre” y "humanidad" a lo largo del desarrollo del trabajo. Sin desconocer la importancia que han subrayado teóricas feministas sobre la política del nombrar y la violencia simbólica que subyace en la supresión 
del lenguaje las diferencias de género, me abstuve de hacer la debida distinción entre hombre y mujer como una elección estrictamente metodológica. De manera compartida, considero necesario la tarea de desmontar todo tipo de dominación que se base en la distribución de privilegios naturalizados de raza, género, sexo, etnia, entre otros sistemas de clasificación igualmente poderosos. Por su puesto, las divisiones de género y el respectivo ordenamiento sociobiologico que produce el patriarcado, están en el centro de estos ensamblajes históricos de poder llamados a ser desestabilizados. Por lo tanto, no quisiera desconocer la centralidad y latencia que tiene esa otra frontera biologizada en la gran máquina del ordenamiento y disposición de lo "viviente", pero considero que esta otra disputa amerita una evaluación con elementos teóricos, temáticos y prácticos que escapan del alcance de este artículo.

\section{Referencias}

Agamben, G. (2006). Lo abierto. Buenos Aires: Adriana Hidalgo.

Las corridas de toros en Bogotá: cambio de tercio (11 de marzo de 2012) Semana. Recuperado el 28 de febrero de 2016, de http://www. semana.com/nacion/articulo/las-corridastoros-bogota-cambio-tercio/267354-3

Espósito, R. (2007). El enigma de la bipolítica. Buenos Aires: Amorrortu.

Foucault, M. (1977). Historia de la sexualidad, 1. La voluntad de saber. México: Siglo XXI.

Hall, S. ([1997] 2014). "El espectáculo del 'otro”. En: Restrepo, Eduardo, Walsh, Catherine y Vich, Víctor (Ed.). Sin garantías: Trayectorias y problemáticas en estudios culturales (2da ed.). Popayán/Bogotá/ Lima/Quito: Envión, Instituto de Estudios Peruanos Instituto de Estudios Sociales y Culturales, Pensar, Universidad Andina Simón Bolívar Sede Ecuador. 459-487
Ospina, L. (11 de marzo de 2012). Páginas sociales: tauromaquia y poder. La silla vacía. Recuperado de http://www.lasillavacia.com/ elblogueo/lospina/32034/paginas-socialestauromaquia-y-poder

Schmucler, H. (2011). La industria de lo humano. Artefacto. Pensamiento sobre la técnica. 4, 1-16.

Steiner, G. (2008). Del hombre y la bestia. My unwritten books. New York: New Direction. 